\section{Política de saúde e gestão no processo de (re)construção do SUS em município de grande porte: um estudo de caso de São Paulo, Brasil}

\author{
Health policy and management in the \\ (re)construction of the Unified National Health \\ System (SUS) in a large municipality: a case study \\ of São Paulo, Brazil
}

Nicanor R. S. Pinto 1,2

Oswaldo Yoshimi Tanaka 1

Sandra Maria Spedo 1,2

\footnotetext{
${ }_{1}^{1}$ Faculdade de Saúde Pública, Universidade de São Paulo, São Paulo, Brasil. 2 Departamento de Medicina Preventiva, Universidade Federal de São Paulo São Paulo, Brasil.

Correspondência N. R. S. Pinto Departamento de Medicina Preventiva, Universidade Federal de São Paulo. Rua Botucatu 740, São Paulo, SP 04023-062, Brasil. nicanor@medprev.epm.br
} 
Saúde e do Estado de São Paulo (Departamento de Informática do SUS. Sistema de Informações sobre Orçamentos Públicos em Saúde. http:// siops.datasus.gov.br, acessado em 25/Abr/2008).

Para uma melhor compreensão do contexto local e do que ocorreu na saúde nesse município nos últimos anos, é necessário resgatar o processo histórico da gestão municipal, em particular, a partir do período 1989-1992, no qual se identifica a primeira tentativa de implantar uma política de saúde alinhada ao SUS. Essa política foi implementada concomitantemente ao processo de institucionalização do próprio SUS no país. Vale lembrar que a legislação que regulamentou o SUS - Leis Federais $n^{o} .8 .080^{2}$ e $n^{o} .8 .142^{3}$ - foi promulgada entre setembro e dezembro de 1990. Foi nesse contexto, com uma base de sustentação jurídico-legal ainda frágil e em uma situação política complexa e desfavorável na sua relação com as esferas federal e estadual de governo, que a gestão municipal de São Paulo implantou uma política de saúde orientada pelos princípios e diretrizes constitucionais do SUS.

Até 1988, a organização político-administrativa da Secretaria Municipal de Saúde (SMS-SP) era centrada em duas estruturas departamentais: o Departamento de Saúde da Comunidade, que coordenava postos de atendimento médico, e a Superintendência Médico-Hospitalar de Urgência, que coordenava prontos-socorros e hospitais. A gestão 1989-1992 promoveu uma reorganização da SMS-SP, descentralizando suas atribuições político-administrativas em dez Administrações Regionais de Saúde e 32 Distritos de Saúde, que, em virtude da concomitante descentralização orçamentária e financeira, ganharam relativa autonomia e agilidade para gastos, incluindo-se contratação de pessoal 4,5,6. Ao final dessa gestão, todos os estabelecimentos de saúde do município - hospitais, prontos-socorros, ambulatórios de especialidades e UBS (unidade básica de saúde) - encontravam-se subordinados a e coordenados pelos Distritos de Saúde de sua região; estes, por serem unidades orçamentárias ${ }^{4}$, tinham inclusive mais autonomia.

Concomitantemente ao rearranjo de sua estrutura organizacional, a direção da SMS-SP buscou abrir um processo de negociação com a Secretaria de Estado da Saúde de São Paulo (SES-SP), visando a iniciar a municipalização das UBS estaduais e a construção de um comando único da rede básica no município. Contudo, devido a contradições e conflitos político-partidários, essa política ficou limitada à transferência para o município de cerca de 50 UBS estaduais 4, que representavam aproximadamente $18 \%$ das que estavam em atividade no Município de São Paulo.
No período 1993-1996, com uma forte orientação gerencialista 7 , foi implementada uma nova política de gestão pública justificada pelo argumento da necessidade de aumentar a eficiência da máquina pública. Um novo modelo assistencial e de gestão da saúde - o Plano de Atendimento à Saúde - foi implantado no último ano dessa gestão 4,8 , após três anos de conflitos e embates políticos no legislativo que contribuíram para postergar sua institucionalização. Nesse período, a maioria dos serviços e estabelecimentos de saúde, de caráter assistencial, vinculados a SMSSP - 16 hospitais, 16 prontos-socorros, 14 ambulatórios de especialidades e 99 UBS -, foi cedida para cooperativas privadas de profissionais de saúde, organizadas exclusivamente para esse fim, à exceção das 50 UBS municipalizadas 4,8,9.

Submetida ao Plano de Atendimento à Saúde, a assistência à saúde no Município de São Paulo foi organizada em 14 módulos assistenciais regionais. Cada módulo coordenava de 7 a 14 UBS e, pelo menos, um hospital e um pronto-socorro, os quais funcionavam como referência regional. O Plano foi financiado com recursos da SMSSP, alocados a cada módulo por mecanismo de capitação: inicialmente, por população coberta estimada, que, depois, deveria evoluir para população efetivamente cadastrada, com um valor fixo per capita por ano 4,8,9. É importante ressaltar que, após denúncia e pressão do Conselho Municipal de Saúde junto ao Conselho Nacional de Saúde, o Ministério da Saúde suspendeu seus repasses financeiros para o município. A partir desse momento, os recursos que financiaram o Plano de Atendimento à Saúde eram oriundos quase exclusivamente da receita do próprio município.

Esse modelo assistencial e de gestão, além de não respeitar princípios constitucionais do SUS, aprofundou contradições e conflitos entre a política do Município de São Paulo e as políticas estadual e nacional de saúde. Nesse contexto, a gestão que iniciou em 2001 assumiu o compromisso político de extinguir o Plano de Atendimento à Saúde e reconstruir o SUS no Município de São Paulo.

Neste artigo, buscou-se explorar a continuidade das políticas implementadas, por duas gestões municipais de distintas frentes partidárias. Deve-se considerar que, em democracias representativas, com a possibilidade de alternância de partidos políticos nos governos, pode haver mudanças de políticas ou de prioridades.

Assim, os objetivos centrais deste estudo foram identificar e avaliar as políticas de saúde priorizadas pelo Município de São Paulo, no processo de reconstrução do SUS, que tiveram sustentação política nas gestões posteriores a 2001. 


\section{Métodos}

Este estudo abarcou duas administrações do Município de São Paulo, no período 2001-2008. A primeira desencadeou o processo de reconstrução do SUS nesse município; a segunda manteve o município no SUS, mas apresentou propostas de mudanças na gestão da política municipal de saúde.

Optou-se pela estratégia metodológica do estudo de caso, que é caracterizado como uma investigação empírica sobre um fenômeno contemporâneo complexo, em seu contexto, especialmente quando os limites entre o fenômeno e o contexto não estão claramente definidos 10 . Em face dessas características, essa estratégia tem sido utilizada em pesquisas sobre política e administração públicas, particularmente no setor saúde 10,11.

O trabalho de campo foi desenvolvido entre julho de 2005 e junho de 2008, tendo contemplado a identificação e a coleta de dados por meio de distintas fontes e estratégias: entrevistas com informantes privilegiados, documentos de gestão e observação participante. Nesse percurso, foram enfrentadas dificuldades para $o$ acesso a alguns documentos internos de gestão e para a realização de entrevistas com gestores e técnicos em situação de gestão. A obtenção de informações da administração 2005-2008 foi mediada por interlocutor da assessoria do gabinete do secretário, estrutura de nível central da SMS-SP.

O material analisado constava de documentos oficiais publicados ou disponibilizados em meios oficiais - diário oficial do município e sítio da SMS-SP na internet - e aqueles publicados, de forma autoral, por atores institucionais da gestão, ou ainda aqueles não publicados fornecidos por técnicos e assessores da SMS-SP.

Foram realizadas entrevistas semi-estruturadas, utilizando-se para tanto um roteiro básico com pontos considerados centrais, em torno dos quais os autores exploraram questões mais relevantes, o que permitiu detalhar temas de interesse. Essas entrevistas, realizadas no período entre março de 2006 e julho de 2007, foram conduzidas por, pelo menos, dois dos autores; um ex-gestor não foi entrevistado pelo fato de existirem informações impressas e autorais de seu período de gestão. Todas foram gravadas e, posteriormente, transcritas por um assistente de pesquisa. A duração variou entre 60 até cerca de 100 minutos.

A observação participante foi desenvolvida em reuniões do Conselho Municipal de Saúde de São Paulo, em Conferências Municipais de Saúde e em encontros com gestores e técnicos da gestão do período estudado. Essa atividade foi complementada pelo registro sistemático das informações.

Com o apoio dessas técnicas, buscou-se compreender as relações entre "intenções", construídas e expressas na formulação das políticas, e "ações", que são expressão da vida real e estão presentes na fase de implementação dessas políticas 11.

Para tanto, duas categorias analíticas centrais foram consideradas: política de saúde e gestão em saúde. O conceito de política de saúde adotado abrange questões relativas tanto ao poder propriamente dito, envolvendo processos eminentemente contraditórios e conflituosos, quanto ao estabelecimento de diretrizes, planos e programas de saúde. O conceito de gestão em saúde contempla questões de criação e de utilização de meios para concretizar os princípios de organização da política 12 .

A identificação e a eleição das políticas priorizadas pela SMS-SP, no período estudado, foram realizadas por meio de recortes temáticos sobre o conteúdo dos dados coletados, com base em três critérios centrais: destaque no discurso de gestores ou em documentos de gestão, continuidade nas duas gestões analisadas e concordância de escolha entre os autores.

$\mathrm{O}$ projeto da pesquisa, que gerou os dados analisados neste artigo, foi aprovado pelos Comitês de Ética em Pesquisa da Faculdade de Saúde Pública, Universidade de São Paulo (FSP/USP), e da SMS-SP (Processo CEP/SMS no. 0084.0.162.207-05), com base na Resolução $n^{\circ}$. 196/96 do Conselho Nacional de Saúde.

\section{Resultados}

No período 2001-2004, a SMS-SP teve dois secretários titulares, cada um com período médio de gestão de 24 meses. No período 2005-2008, quatro secretários alternaram-se na direção da SMSSP, com períodos de gestão que variaram entre 5 e 17 meses. Considerando-se todo o período estudado, a duração média dos gestores da saúde foi de aproximadamente 13 meses, variando de cinco até 24 meses. O perfil profissional e uma breve trajetória da vida pública desses gestores da saúde municipal encontram-se relacionados na Tabela 1 .

Com base nos critérios citados anteriormente, foram identificadas as principais políticas priorizadas pelas duas gestões municipais estudadas: (a) reincorporação do Município de São Paulo ao SUS; (b) reorganização administrativa da SMS-SP e (c) expansão do Programa Saúde da Família (PSF) no município (Tabela 2). 
Tabela 1

Perfil profissional e trajetória pública dos titulares da Secretaria Municipal de Saúde. São Paulo, Brasil: 2001-2008.

\begin{tabular}{|c|c|c|}
\hline Gestor & Perfil profissional & Trajetória pública \\
\hline A & $\begin{array}{l}\text { - Médico, com especialização em Saúde Pública } \\
\text { - Médico sanitarista (SES-SP) }\end{array}$ & $\begin{array}{l}\text { - Deputado Estadual (SP - 1983-1987) } \\
\text { - Deputado Federal (SP - 1988-2003) } \\
\text { - Secretário - SMS de município de grande porte (SP - 1989-1990) } \\
\text { - Secretário - SMS-SP (2001-2002) }\end{array}$ \\
\hline B & $\begin{array}{l}\text { - Médico, com especialização e mestrado em } \\
\text { - Pdministração Hospitalar } \\
\text { hospitalar (hospitais público e privados) }\end{array}$ & $\begin{array}{l}\text { - Chefe de gabinete - SMS de município de grande } \\
\text { porte (SP - 1993-1994) } \\
\text { - Diretor superintendente de hospital de clínicas em município } \\
\text { de grande porte (SP - 1997-1998) } \\
\text { - Diretor-presidente de agência nacional da área de Regulação } \\
\text { da Saúde (1999-2002) } \\
\text { - Secretário - SMS-SP (2003-2004) }\end{array}$ \\
\hline C & $\begin{array}{l}\text { - Médico, com especialização, mestrado e doutorado } \\
\text { em Oftalmologia } \\
\text { - Médico e administrador hospitalar (hospital privado) e } \\
\text { professor (universidade pública) }\end{array}$ & $\begin{array}{l}\text { - Presidente de sociedade beneficente mantenedora de } \\
\text { hospital privado (2000-atual) } \\
\text { - Secretário - SMS-SP (2005) }\end{array}$ \\
\hline $\mathrm{D}$ & $\begin{array}{l}\text { - Médica, com especialização e doutorado em Pediatria } \\
\text { - Professor (universidade privada) e médico (SES-SP) }\end{array}$ & $\begin{array}{l}\text { - Diretor de Faculdade de Medicina (1995-atual) } \\
\text { - Diretor-superintendente de hospital geral, organização social da } \\
\text { saúde da SES-SP (1998-atual) } \\
\text { - Secretário - SMS-SP (2005-2006) }\end{array}$ \\
\hline$E$ & $\begin{array}{l}\text { - Médica, com especialização em Direito Sanitário } \\
\text { - Médico (Ministério da Saúde) }\end{array}$ & $\begin{array}{l}\text { - Diretor de departamento nacional do Ministério da Saúde da } \\
\text { área de Avaliação e Controle do SUS (1999-2002) } \\
\text { - Coordenador de programa de atenção específico da SMS de } \\
\text { município de grande porte (SP - 2005-2006) } \\
\text { - Secretário - SMS-SP (2006-2007) }\end{array}$ \\
\hline $\mathrm{F}$ & $\begin{array}{l}\text { - Administrador de empresas } \\
\text { - Administrador (empresa pública da área de Energia Elétrica) }\end{array}$ & $\begin{array}{l}\text { - Secretário Municipal de Recursos Humanos e da Administração } \\
\text { de município de grande porte (SP - 1993-1999) } \\
\text { - Diretor-presidente de agência nacional da área de Regulação } \\
\text { da Saúde (1999-2003) } \\
\text { - Secretário Municipal da gestão pública de município de grande } \\
\text { porte (SP - 2005-2007) } \\
\text { - Secretário - SMS-SP (2007-2008) }\end{array}$ \\
\hline
\end{tabular}

SP: São Paulo; SMS: Secretaria Municipal de Saúde; SES-SP: Secretaria de Estado da Saúde de São Paulo; OSS: organização social de saúde.

\section{Reincorporação do Município de São Paulo ao SUS}

Esta pode ser caracterizada como política prioritária da gestão municipal, iniciada em 2001, que foi implementada por meio de três eixos principais: a reorganização das instâncias de participação e controle sociais, a extinção do antigo Plano de Atendimento à Saúde e a municipalização da rede básica estadual.

A participação social foi implementada, desde 2001, por meio da reinstitucionalização das instâncias formais de controle social do SUS no município: Conselho Municipal de Saúde, Con- ferências Municipais de Saúde e Conselhos Gestores de Unidades. Esse processo foi destacado pelo gestor do período como: “A democratização partiu dos sobreviventes/resistentes do Conselho Municipal de Saúde (...) que haviam sido esmagados nos anos anteriores (...) De trinta conselheiros fomos para mais de 4000, (...) com dezenas de cursos de formação sobre o SUS” 13 (p. 27).

As duas gestões municipais mantiveram essa política e suas instâncias formais. No período, foram realizadas quatro Conferências Municipais de Saúde, duas por cada gestão, e reuniões do Conselho Municipal de Saúde com relativa regularidade. Não sem conflitos, como a crise ins- 
Políticas identificadas como prioritárias e seus eixos principais. São Paulo, Brasil, 2001-2008.

\begin{tabular}{|c|c|}
\hline Política (período) & Eixo \\
\hline Reincorporação do Município de & - Reorganização e manutenção das instâncias de participação e controle sociais. \\
\hline \multirow[t]{4}{*}{ São Paulo ao SUS (2001-2008) } & • Extinção do Plano de Atendimento à Saúde. \\
\hline & - Municipalização de 200 UBS estaduais: 141 (2001); 59 com PSF/Qualis (2002). \\
\hline & • Habilitação do Município de São Paulo: na gestão plena da atenção básica (Fev/2001); \\
\hline & na gestão plena do sistema municipal de saúde (Jun/2003). \\
\hline \multirow{3}{*}{$\begin{array}{l}\text { 1ạ reorganização administrativa da SMS-SP } \\
\text { (2001-2004) }\end{array}$} & - Distritalização dos serviços ambulatoriais: criação de 41 distritos de saúde (2001), \\
\hline & redimensionados para 31 coordenadorias de saúde vinculadas às subprefeituras (2002). \\
\hline & - Autarquização dos hospitais e postos de saúde municipais: criação de 5 autarquias hospitalares. \\
\hline 2a reorganização administrativa da & • Extinção das 31 coordenadorias de saúde. \\
\hline \multirow[t]{5}{*}{ SMS-SP (2005-2008) } & - Criação de 5 coordenadorias regionais de saúde. \\
\hline & - Criação de 24 supervisões técnicas de saúde, subordinadas a 5 coordenadorias \\
\hline & regionais de saúde. \\
\hline & - Manutenção das 5 autarquias hospitalares; reorganizadas funcionalmente em 2 \\
\hline & (uma assistencial; outra administrativa - 2007-2008). \\
\hline \multirow[t]{5}{*}{ Expansão do PSF (2001-2008) } & - 159 equipes do PSF/Qualis implantadas (dez/2000), expandidas para 850 equipes \\
\hline & do PSF (Jun/2008). \\
\hline & - Parceria da SMS-SP com entidades privadas: gestão de pessoal do PSF (seleção, contratação \\
\hline & e capacitação) e contratação de serviços de apoio diagnóstico (2001); ampliação para a \\
\hline & gerência de estabelecimentos (hospitalares e ambulatoriais) (2006-2007). \\
\hline
\end{tabular}

UBS: unidades básicas de saúde; PSF: Programa Saúde da Família; SMS-SP: Secretaria Municipal de Saúde de São Paulo.

talada com o questionamento da SMS-SP sobre a representatividade de parte do segmento dos usuários, que quebrou a institucionalidade do Conselho Municipal de Saúde por aproximadamente quatro meses, no início de 2008. Essa crise só foi superada após a intermediação do Ministério Público Estadual 14

A extinção do Plano de Atendimento à Saúde, que foi concluída em junho de 2001, e os esforços despendidos nesse processo foram caracterizados nos seguintes termos: "No ano de 2001, primeiro ano de governo, a capital paulista passa a integrar-se, finalmente, junto a tantos outros municípios brasileiros no esforço nacional de construção do Sistema Único de Saúde. Tarefa árdua, desafiadora e prioridade $n^{\circ} .1$ na Área da Saúde no Governo da Reconstrução" (Relatório de Gestão SMS-SP 2002).

No mesmo relatório, a situação e dificuldades encontradas, bem como a transição implementada, foram caracterizadas pelo gestor municipal da época com as seguintes palavras: " $A$ SMS encontrava-se fraturada em três segmentos (...) 17 mil trabalhadores do Plano de Atendimento à Saúde divididos entre 12 mil contratados em situação trabalhista irregular perante a lei e 5 mil funcionários estáveis da Prefeitura; 13 mil trabalhadores da saúde que restaram (...); 10 mil trabalhadores da saúde 'exilados' da Secretaria Municipal de Saúde (...) nos diversos cantos da máquina administrativa" (Relatório de Gestão SMS-SP 2002).

Nesse contexto e associado ao compromisso de extinguir o Plano de Atendimento à Saúde, impôs-se o desafio de regularizar a situação funcional desse contingente de pessoal, o que exigiu "uma megamovimentação de pessoal feita com o máximo de prudência e tolerância (...). Uma transição respeitando a lei municipal e os prazos dos contratos das cooperativas" 13 (p. 12).

O reconhecimento do Município de São Paulo como gestor único da atenção básica foi outro eixo dessa política, que imprimiu marca e identidade com o SUS, e foi expresso pelo rápido processo de negociação política com a SES-SP e o Ministério da Saúde, habilitando o município na condição de Gestão Plena da Atenção Básica, já em fevereiro de 200115.

Como desdobramento desse processo, foi implementada a municipalização da rede básica estadual, em dois momentos distintos: no período entre junho e dezembro de 2001, foram municipalizados 141 UBS e 12 ambulatórios de saúde mental; em abril de 2002, foram municipa- 
lizadas outras 59 UBS, com cerca de 200 equipes do PSF/Qualis 15. Com base nesse quadro, o gestor da época avaliou que: "O diálogo rompido foi retomado e (...) todas as unidades básicas estaduais sediadas na capital (200) estão funcionando articuladas com as unidades básicas municipais (150) sob a gerência unificada da SMS" 13 (p. 13).

Após a municipalização da rede básica estadual, essa gestão pleiteou a habilitação do município na condição de gestão plena do sistema municipal de saúde.

"Em novembro de 2002, a Secretaria deu entrada no pedido de gestão plena. Estão em andamento as negociações do repasse para a nossa gerência dos quarenta hospitais estaduais e outros tantos serviços especializados estaduais sediados na capital e também o acompanhamento dos serviços de saúde privados, filantrópicos e lucrativos, conveniados com o SUS na cidade" 13 (p. 13).

No entanto, a habilitação do Município de São Paulo na condição de gestão plena do sistema municipal de saúde só foi viabilizada em 2003 16, após a mudança do gestor da saúde municipal. Em que pese a complexidade da rede pública estadual de saúde e dos prestadores privados no município, em virtude de limitações orçamentárias e financeiras, a SMS-SP pactuou uma gestão plena do sistema municipal de saúde que teve precária participação financeira da SES-SP, como se percebe no relato do gestor do período: "Nós entramos na batalha da municipalização (...), de certa maneira, sozinhos. O Estado, num primeiro momento, topou entrar, mas não queria rediscutir nenhuma distribuição de recursos. (...) Falaram: 'Olha, vocês chegaram por último. E quem chega por último (na festa), come o que tem'. (...) 'O que sobrou da Programação Pactuada Integrada do Estado é isso (...)'. O secretário executivo do Ministério conseguiu minimizar esse impasse (...) retirou recursos de outros locais do país e alocou em São Paulo" (gestor B).

Nesse sentido, o mesmo gestor apresentou a fragilidade da gestão plena assumida, nos seguintes termos: "Como é que dá para discutir a questão da integralidade, se uma parte da rede ambulatorial especializada não tem nada a ver com a prefeitura? (...) Se meu acesso hospitalar não tem nenhum nexo com o processo de atenção à saúde? Quero dizer, se a porta de entrada à dimensão hospitalar é o pronto-socorro?" (gestor B).

Uma variável conjuntural importante, identificada no contexto político da época, foi que "Na hora que o movimento da eleição começou, azedou tudo! (...) A partir de abril/maio de 2004, essas coisas foram congeladas e não avançamos mais, praticamente, nada" (gestor B).

Com base nesses depoimentos, pode-se observar que o Município de São Paulo teve que as- sumir uma gestão plena do sistema municipal de saúde sem lograr qualquer avanço na gestão ou municipalização dos serviços de saúde de média e alta complexidades estaduais ou outros prestadores sob gestão estadual.

\section{Reorganização administrativa da SMS-SP}

Cada gestão analisada implementou uma reestruturação administrativa na Secretaria, visando à adequação da estrutura existente para a implementação dos projetos prioritários de governo.

A primeira reorganização da SMS-SP teve início em 2001 e sua implantação compreendeu dois eixos principais: a descentralização administrativa da rede ambulatorial e uma nova conformação da rede de hospitais e de prontos-socorros municipais.

A descentralização da gestão da rede ambulatorial foi implementada por meio da criação de 41 Distritos de Saúde, por ato do secretário, em janeiro de 2001. A gestão municipal justificou a necessidade desse processo, caracterizado na época como "distritalização", por avaliar que: "Não é possível uma operação de municipalização... mantendo as atuais estruturas dos cinco núcleos em que se divide a Administração Estadual aqui na capital e as dez Administrações Regionais de Saúde (...), levando-se em conta os limites dos 96 Distritos Administrativos da cidade (...) para compatibilizar os nossos 41 Distritos nos limites das futuras prefeituras regionais" 17 (p. 10-1).

Em 2002, como desdobramento da descentralização político-administrativa da prefeitura de São Paulo com a criação de 31 Subprefeituras, os 41 Distritos de Saúde iniciais foram reorganizados em 31 Coordenadorias de Saúde e vinculados às novas subprefeituras 18,19. As competências dessas instâncias eram limitadas à coordenação das UBS e dos ambulatórios de especialidades.

Em 2004, na tentativa de superar críticas sobre uma potencial duplicidade de comando entre o gestor municipal da saúde (SMS) e o gestor regional do município (subprefeitura), foi promulgado um decreto específico, determinando que "O Secretário Municipal da Saúde é o dirigente único do Sistema Único de Saúde no Município de São Paulo, cabendo a ele manter a unicidade conceitual e política do Sistema" 20 (p. 1).

Paralelamente à distritalização, foram criadas cinco autarquias hospitalares 21. Uma das justificativas para tanto, foi a situação encontrada em 2001, refletida nas dificuldades relatadas por um informante privilegiado da área de gestão hospitalar, no trecho que segue: "Com a extinção do Plano de Atendimento à Saúde e a demissão do pessoal contratado irregularmente, o hospital $X$ não tinha o pessoal mínimo necessário para 
mantê-lo em funcionamento". Já o gestor municipal do período avaliou essa reforma da SMS-SP como o resultado da "coragem de inventar novas formas ou reinventar velhas formas, adaptandoas a nossa realidade", caracterizando-a como uma "modernização da gestão" 13 (p. 13-4).

A segunda reorganização administrativa da SMS-SP foi implementada como uma das primeiras medidas do novo governo municipal eleito, iniciado em 2005. Com uma justificativa racionalizadora para a mudança, o gestor do período relatou sua avaliação sobre a estrutura administrativa da saúde encontrada no município: "Na Secretaria, (...) secretário da saúde lidera um grupo de cinco autarquias. Essas autarquias têm um grupo de 15 hospitais e alguns prontossocorros. (...) Cada subprefeitura tinha um coordenador de saúde que, ao invés de se reportar ao secretário da saúde, se reportava ao subprefeito. (...) Sob o sentido da racionalização de recursos, é absolutamente fora de propósito! (...) Não poderia existir um coordenador de saúde que trabalha longe do secretário da saúde. E, pior, um sistema ambulatorial que não conversa com o sistema hospitalar!" (gestor C).

E, em face da situação encontrada, o mesmo gestor justifica as medidas adotadas: "Vamos acabar com essa história de ter um subsecretário para cada região. (...) Daí, a razão de acabarmos com as coordenadorias e criar cinco coordenadorias regionais. (...) Eram cinco autarquias hospitalares. (...) Vou acabar com essa história de um ambulatório separado do hospital e vou criar essa integração!" (gestor C).

Dessa forma, sem fazer uma reforma administrativa formal, a nova gestão nomeou apenas cinco coordenadores de saúde, em uma estrutura que previa 31 cargos de coordenadores. $\mathrm{Na}$ prática, foi implementada uma reforma funcional, ampliando-se a responsabilidade de cada coordenador para um território abrangendo de quatro até sete subprefeituras 22 . Em outubro de 2005, um decreto transferiu as coordenadorias das subprefeituras para a SMS-SP, oficializando as cinco Coordenadorias Regionais de Saúde, e criando 24 Supervisões Técnicas de Saúde subordinadas às primeiras 23 . Contudo, essa gestão manteve as competências dessas instâncias limitadas à coordenação dos serviços ambulatoriais.

Apesar do discurso manifesto, as autarquias hospitalares foram mantidas. Em março de 2006, outro decreto alterou sua denominação e instituiu a integração formal das cinco Coordenadorias Regionais de Saúde com a Rede Hospitalar Municipal, de acordo com sua localização geográfica 24. Por fim, em 2008, essas instâncias foram reorganizadas, funcionalmente, em apenas duas autarquias: uma de caráter administrativo e outra de coordenação técnica dos hospitais municipais.

\section{Expansão do PSF no município}

Em dezembro de 2000, o Município de São Paulo tinha 159 equipes de saúde da família cadastradas e uma cobertura populacional estimada em $5,5 \% 25$. Todas estavam sob gestão da SES-SP e eram denominadas PSF/Qualis. A partir de 2001, com a municipalização das UBS estaduais, a expansão do PSF foi assumida pela gestão como prioridade e principal estratégia de mudança do modelo assistencial do SUS na cidade (Figura 1). A relevância dessa política pode ser observada no discurso do gestor do período: "Nossa opção para o modelo de atenção foi apostar alto no potencial revolucionário do Programa de Saúde da Família. (...) Adesão dos usuários, sua capacidade de humanizar as relações profissional de saúdel cidadão usuário, sua força racionalizadora da rede hospitalar e especializada com a rede básica, mostraram o acerto de nossa escolha política e orçamentária" 13 (p. 28).

A prioridade dada a essa política por esse gestor pode ser identificada no relato de um informante privilegiado, do gabinete da SMS-SP, que o caracterizou como um secretário que "transpirava PSF por todos os poros! Era PSF, PSF (...) Tudo era PSF!". O caráter e a importância dados ao PSF por essa gestão foram documentados da seguinte forma: "A SMS terá sua rede básica gradativamente transformada pela estratégia da Saúde da Família nos próximos quatro anos. (...) É diretriz da SMS implantar a estratégia da Saúde da Família nas UBS, com meta de cobertura de 60\% da população" 26.

A institucionalização desse programa se deu por meio da Portaria $n^{o}$. 3.822 27, segundo a qual a meta de cobertura especificada foi a implantação de 1.749 equipes até 2004. Apesar dos esforços para implementar essa política, a meta estabelecida mostrou-se difícil de ser atingida. Na prática, o Ministério da Saúde registrava um total de 619 equipes de saúde da família implantadas no Município de São Paulo, em dezembro de 2004, e estimava sua cobertura populacional em $20 \% 25$.

A gestão municipal do período 2005-2008 continuou expandindo o PSF, atingindo um total de 850 equipes de saúde da família implantadas até junho de 2008, o que representava $26,6 \%$ de cobertura populacional 25. Pode-se observar que o ritmo de implantação do PSF no município não foi regular, apresentando variações entre as duas gestões estudadas (Figura 1).

Uma das estratégias utilizadas para a expansão do PSF no Município de São Paulo foi instalar as equipes de saúde da família nas UBS muni- 
Figura 1

Evolução trimestral das equipes de saúde da família implantadas. São Paulo, Brasil: 2000-2008.

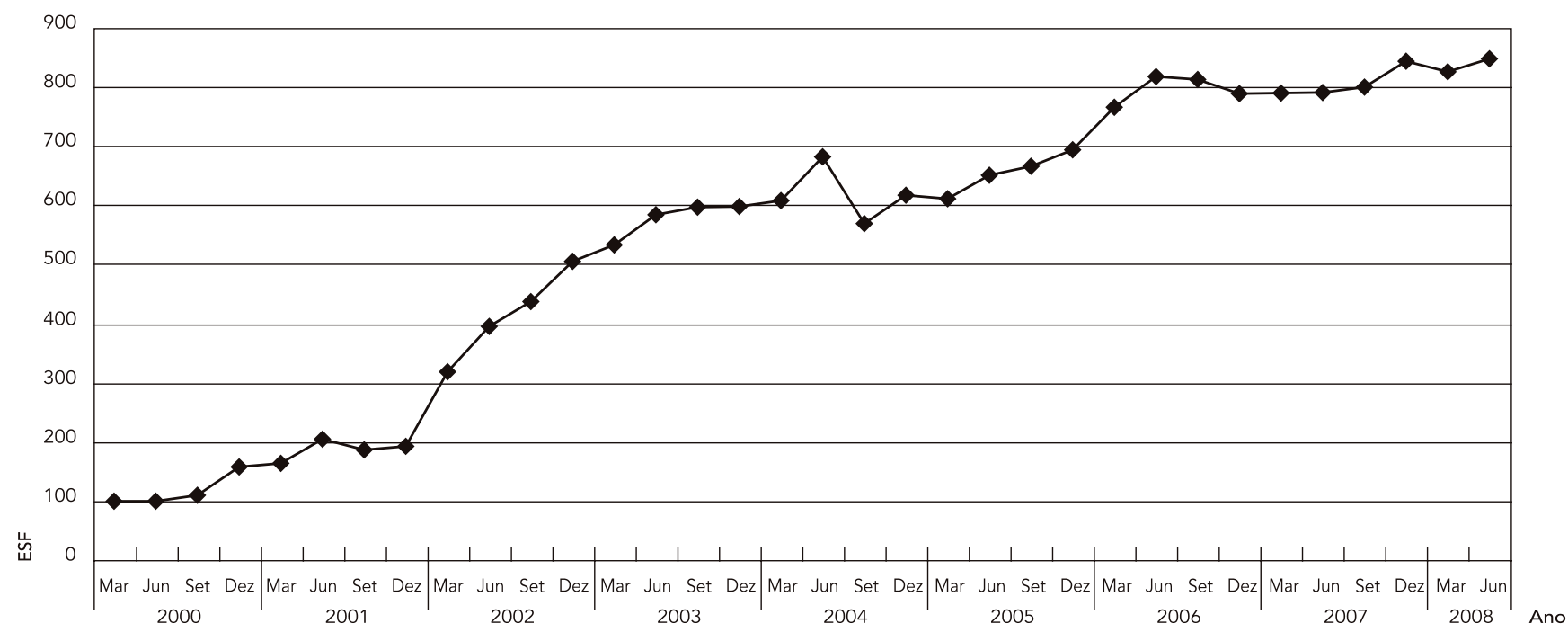

Fonte: Departamento de Atenção Básica, Ministério da Saúde 25.

cipais ou municipalizadas, transformando esses estabelecimentos, seja em unidades de saúde da família, seja em unidades "mistas". Nestas, as equipes de saúde da família passaram a conviver com equipes ditas "tradicionais", compostas por médicos pediatras, ginecologistas e clínicos; algumas com médicos sanitaristas, psiquiatras, psicólogos, fonoaudiólogos, fisioterapeutas. Contudo, essa estratégia não conseguiu expandir a implantação do programa e ampliar o acesso em áreas descobertas de serviços, como se pode deduzir do comentário de um dos gestores do período: "A instalação dos PSF na cidade, apesar de ter sido concentrada na periferia, tem três equipes aqui, tem uma lá na Vila Madalena, tem uma do lado da Escola Paulista de Medicina. Enfim, houve uma expansão, não totalmente crítica do PSF na cidade. (...) Não conseguiu saturar áreas porque abriu tantas frentes no início. Isso transformou muitas regiões da cidade num 'queijo suiço'”' (gestor B).

Outra estratégia adotada pelas duas gestões municipais para a implementação dessa política foi a manutenção das mesmas parcerias com entidades privadas, que intermediaram a gestão de pessoal do programa, tanto para seleção e contratação, quanto para sua capacitação. Assim, a SMS-SP manteve as quatro entidades parceiras da SES-SP, para a implantação do PSF/Qualis, e ampliou esse número para 12, ainda em 200128 . Todas foram mantidas pela gestão 2005-2008, exceto uma que atingiu situação falimentar em 2007 e foi substituída. Neste último período, a coordenação das equipes do PSF deixou de ser atribuição de pessoal de carreira da SMS-SP e foi transferida para as entidades parceiras.

\section{Discussão}

Desde 2001, o Município de São Paulo vem implementando políticas de saúde que respeitam os princípios constitucionais da universalidade, particularmente de acesso à atenção básica, e da participação e controle social do SUS. Em relação à integralidade, na sua dimensão sistêmica, em que pese o fato de o município ter uma relevante quantidade de serviços e equipamentos instalados em seu território, é fundamental que sejam superadas as precárias condições nas quais o município foi habilitado como gestão plena do sistema municipal de saúde, para que possa assumir a gestão de todas as ações e serviços de fato.

Uma das variáveis intervenientes relacionase com a política municipal de saúde das gestões 1993-2000, que criou o Plano de Atendimento à Saúde como um sistema assistencial paralelo 
que não respeitava os princípios do SUS. Concomitantemente, foi implementada uma progressiva desestruturação da SMS-SP, em particular dos antigos distritos de saúde. Nesse sentido, a mera extinção do Plano de Atendimento à Saúde não foi suficiente para resgatar a estrutura organizacional anterior à sua implantação.

Em relação ao pessoal técnico da SMS-SP, não houve o retorno ou reposição daqueles que haviam sido absorvidos por outras secretarias, principalmente em áreas como a jurídico-legal e financeiro-contábil. O depoimento de um dos gestores do período corrobora essa análise: “ $A$ melhor estrutura gerencial das três esferas de governo era a estrutura do município. Na saúde, ela foi destruída. Quem foi embora, com o Plano de Atendimento à Saúde, voltou quando era da área fim. Os da área meio nunca mais voltaram. (...) A burocracia não voltou mais. (...) A secretaria, até hoje, não se recuperou. (...) Aquele departamento de apoio técnico, (...) pode ser dito que era um relógio. Barulhento, atrasava um pouco, mas era um relógio" (gestor B).

Não foi possível identificar, nas duas gestões estudadas, qualquer movimento a fim de resgatar as atribuições e competências dos distritos de saúde organizados na gestão 1989-1992. Observou-se que o processo de reestruturação da SMS-SP não avançou no sentido de superar os entraves existentes para uma efetiva articulação entre distintos serviços públicos de saúde instalados no município. Por um lado, foram estruturadas instâncias administrativas locorregionais, com atribuições e competências limitadas à coordenação e controle das atividades dos estabelecimentos ambulatoriais sob gestão municipal. Por outro lado, a reorganização dos hospitais e prontos-socorros municipais foi implementada por meio da criação de outra estrutura administrativa. E, ainda, foram mantidos diversos serviços estaduais sob gestão, de fato, da SES-SP.

Embora as duas gestões estudadas tenham priorizado e implementado políticas de reestruturação da SMS-SP, o SUS no município ficou fragmentado em três segmentos de estabelecimentos público-estatais, com estruturas de coordenação próprias: (a) os estabelecimentos ambulatoriais sob gestão municipal: ambulatórios de especialidades, UBS e serviços de pronto atendimento tipo AMA (Atendimento Médico Ambulatorial); (b) os estabelecimentos hospitalares e de urgência e emergência sob gestão municipal: hospitais e prontos-socorros; (c) os estabelecimentos sob gestão estadual: ambulatórios e hospitais de especialidades.

Na prática, constatou-se a coexistência de três subsistemas da saúde paralelos, o que representa um importante obstáculo para uma melhor ar- ticulação entre serviços de distintas densidades tecnológicas. Nesse contexto, fica comprometida a efetiva implementação da integralidade da atenção no SUS, no Município de São Paulo. É importante considerar, ainda, que outro fator que fragiliza essa integralidade está relacionado com a tradição, o papel e o poder das instituições presentes nessa arena política, particularmente dos hospitais, por sua relação com o poder médico, por sua relativa autonomia funcional e pela possibilidade de constituir clientelas próprias 29.

Uma variável que deve ser considerada na análise das reorganizações implementadas está relacionada com o perfil profissional e a trajetória pública dos gestores. No período estudado, constatou-se que, dos seis secretários que se alternaram na direção da SMS-SP, apenas três tinham formação profissional na área da saúde pública/coletiva e/ou trajetória vinculada ao processo de construção do SUS no país. Esse fato impõe a necessidade de se aprofundar a discussão sobre a relevância desta variável, na medida em que o conhecimento e o entendimento dos gestores sobre o SUS, enquanto política pública, podem qualificar e fortalecer sua capacidade de governo, conforme identificado por outros autores 30 .

Outra constatação importante deste estudo relaciona-se com a alta rotatividade observada entre os gestores da saúde. Embora possa ter alguma particularidade, essa problemática parece não ser específica das capitais. Assim, avaliamos que essa rotatividade compromete a sustentação das políticas de saúde que fortaleçam o SUS, mesmo em contextos favoráveis, com gestores de saúde qualificados e com alta capacidade de governo.

O PSF foi identificado como uma das políticas priorizadas e que teve continuidade nas duas gestões, com a manutenção, inclusive, da mesma denominação "genérica”. É importante considerar que essa sustentação política pode estar relacionada com o fato de esse programa ser uma prioridade do Ministério da Saúde, com estímulo financeiro vinculado, e, também, por não ter se constituído como uma marca política da primeira gestão municipal. A indução dessa política pelo Ministério da Saúde, por meio de estímulos financeiros aos municípios, configura uma forma de (re)modelar a atenção básica com uma única estratégia em todo o país e pode ser caracterizada como um tipo de isomorfismo institucional 31 .

Apesar dos esforços despendidos, a SMS-SP conseguiu atingir $48,5 \%$ da meta proposta, implantando 850 equipes de saúde da família com uma cobertura populacional de $26,6 \%$. Ainda assim, o programa do Município de São Paulo é o maior do país. Para se ter a dimensão das dificul- 
dades em atingir a meta proposta, deve-se considerar que, mesmo capitais que alcançaram altos níveis de cobertura populacional, como Belo Horizonte, Minas Gerais, com 68,6\% de cobertura, têm um total de 477 equipes de saúde da família implantadas. Por outro lado, o PSF no Município de Fortaleza, Ceará, que é a capital do estado que iniciou a implantação desse programa no país, tem uma cobertura de apenas $25,7 \%$, com 180 equipes de saúde da família 25 , refletindo em boa medida as dificuldades operacionais de implantação do programa em grandes municípios.

A estratégia de (re)modelagem da atenção básica, substituindo as equipes "tradicionais" das UBS pelas equipes de saúde da família, não foi suficiente para proporcionar cobertura à população sem acesso ou com acesso precário a esse nível de atenção. Esses espaços geográficos ou núcleos populacionais desassistidos configuram o que um dos gestores do período caracterizou como buracos do "queijo suíço". Essa situação foi detectada e relatada em outro estudo, que avaliou o PSF no Município de São Paulo 32.

A implantação do PSF por meio de parcerias com entidades privadas, justificada como forma para agilizar a implementação do programa, criou importante contradição. Deve-se considerar que o fundamento da agilidade para a contratação de pessoal, compras e manutenção serve tanto para justificá-las, quanto para agilizar demissões dessa força de trabalho, numa lógica de caráter gerencialista e com critérios que não respeitam o que se convencionou denominar de interesse do bem comum 7,33. Logo, relações trabalhistas precárias ou não estáveis fragilizam o componente da força de trabalho que, no setor saúde, é estratégico e tem potência para dar continuidade e sustentação às políticas, no que se refere à sua configuração como política de Estado.

Para Di Pietro 34, parceria e terceirização são velhas estratégias, com caráter fortemente ideológico, que contribuem para a mudança do papel do Estado e da Administração Pública. Dessa forma, o Estado não teria mais o papel de prestador direto de serviços, sendo necessário limitar suas competências e diminuir seu tamanho, para transformá-lo num Estado cujo papel principal seria o de estimular, apoiar e subsidiar a iniciativa privada 34 .

Portanto, apesar das distintas orientações político-partidárias das gestões estudadas, observou-se que a terceirização de serviços e de estabelecimentos de saúde esteve presente desde o início da primeira gestão, inicialmente centrada no gerenciamento de pessoal para o PSF e na contratação de serviços de apoio diagnóstico. Na segunda gestão, constatou-se um aprofundamento dessa política, chegando à terceirização da gerência de estabelecimentos e até mesmo de regiões de saúde. 


\section{Resumo}

O processo de (re)construção do SUS no Município de São Paulo, Brasil, foi analisado, no período de 2001 2008, por meio de estudo de caso, utilizando-se distintas fontes: documentos; entrevistas com informanteschave e observação participante. Os conceitos de política de saúde e de gestão em saúde foram utilizados na qualidade de categorias analíticas. Foram selecionadas e analisadas apenas políticas priorizadas pela gestão iniciada em 2001 e que tiveram sustentação até 2008. Discutem-se desafios para a (re)construção do SUS no município relacionados com o contexto político-institucional e com mudanças de estrutura implementadas. As reorganizações da Secretaria Municipal de Saúde de São Paulo propiciaram a constituição e manutenção de dois subsistemas municipais, um hospitalar e outro ambulatorial. Negociações entre os governos municipal, estadual e federal não avançaram para que o município assumisse a gestão de fato de todo sistema de saúde, constatando-se a coexistência de três subsistemas públicos de saúde paralelos: dois municipais e um estadual. A sustentação política do Programa Saúde da Família foi associada ao fato de que esse programa não se constituiu como marca da primeira gestão municipal e, ainda, de ser política prioritária e estimulada pelo governo federal.

Política de Saúde; Gestão em Saúde; Sistemas de Saúde; Sistema Único de Saúde

\section{Colaboradores}

N. R. S. Pinto contribuiu na elaboração dos métodos, na análise temática, na discussão dos resultados e na redação final deste artigo. S. M. Spedo e O. Y. Tanaka colaboraram na discussão dos resultados e na redação do artigo.

\section{Agradecimentos}

A pesquisa que gerou os dados analisados neste artigo foi parcialmente financiada, na modalidade apoio à pesquisa, pelo Conselho Nacional de Desenvolvimento Científico e Tecnológico (processo no. 401903/2005-2) e pela Fundação de Amparo à Pesquisa do Estado de São Paulo (processo no. 2005/53846-8).

\section{Referências}

1. Instituto Brasileiro de Geografia e Estatística. Cidades@: São Paulo (SP). http://www.ibge.gov.br/ cidadesat/ (acessado em 25/Jul/2008).

2. Brasil. Lei no ${ }^{\circ} 8.080$ de 19 de setembro de 1990. Dispõe sobre as condições para a promoção, proteção e recuperação da saúde, a organização e o funcionamento dos serviços correspondentes e dá outras providências. Diário Oficial da União 1990; 20 set.

3. Brasil. Lei $\mathrm{n}^{\circ}$. 8.142 de 28 de dezembro de 1990. Dispõe sobre a participação da comunidade na gestão do Sistema Único de Saúde (SUS) e sobre as transferências intergovernamentais. Diário Oficial da União 1990; 31 dez.

4. Junqueira V. Saúde na cidade de São Paulo (1989 a 2000). 2a Ed. São Paulo: Instituto Pólis/Pontifícia Universidade Católica de São Paulo; 2002.

5. Neder C. Organização do SUS em São Paulo: breve histórico. http://www.carlosneder.org.br/CN02/ especiais/ (acessado em 20/Jun/2008).
6. Furtado LAC, Tanaka OY. Processo de construção de um distrito de saúde na perspectiva de gestores e médicos: estudo de caso. Rev Saúde Pública 1998; 32:587-95.

7. Paula APP. Administração pública brasileira: entre o gerencialismo e a gestão social. RAE Revista de Administração de Empresas 2005; 45:36-49.

8. Cohn A, Elias PEM, organizadores. O público e o privado na saúde: o PAS em São Paulo. São Paulo: Cortez Editora/Centro de Estudos de Cultura Contemorânea; 1999.

9. Keinert TMM. Política pública de saúde, inovação e o Plano de Atendimento à Saúde do Município de São Paulo. RAE Revista de Administração de Empresas 1997; 37:78-85.

10. Yin RK. Case study research: design and methods. 2nd Ed. Thousand Oaks: Sage Publications; 1994. 
11. Viana AL. Abordagens metodológicas em políticas públicas. Revista de Administração Pública 1996; 30:5-43.

12. Paim JS, Teixeira CF. Política, planejamento e gestão em saúde: balanço do estado da arte. Rev Saúde Pública 2006; 40 N Esp:73-8.

13. Sobrinho EJMA. Prefácio: São Paulo de volta ao Brasil e à Constituição. In: Sousa MF, Mendes A, organizadores. Tempos radicais da saúde em São Paulo: a construção do SUS na maior cidade brasileira. São Paulo: Editora Hucitec; 2003. p. 11-5.

14. Plenária Municipal de Saúde. Despacho da justiça a favor do Conselho. http://plenariamunicipalsau desp.blog.terra.com.br/?m=200803\&page $=3$ (acessado em 25/Jul/2008).

15. Donnini OA. A reorganização da gestão de saúde em São Paulo. In: Sousa MF, Mendes A, organizadores. Tempos radicais da saúde em São Paulo: a construção do SUS na maior cidade brasileira. São Paulo: Editora Hucitec; 2003. p. 31-42.

16. Brasil. Portaria MS/GM no. 1.399. Habilita o Município de São Paulo conforme o Anexo desta Portaria, na Gestão Plena do Sistema Municipal. Diário Oficial da União 2003; 23 jul.

17. São Paulo. Comunicado SMS nº. 01. Diretrizes gerais para Secretaria Municipal de Saúde - documento 1. Diário Oficial do Município 2001; 25 jan.

18. São Paulo. Lei no ${ }^{\circ}$ 13.399. Dispõe sobre a criação de Subprefeituras no município de São Paulo. Diário Oficial do Município 2002; 2 ago.

19. São Paulo. Comunicado SMS no ${ }^{\circ}$ 87. Adequação do sistema municipal de saúde às Subprefeituras. Diário Oficial do Município 2002; 15 ago.

20. São Paulo. Decreto no. 45.037. Dispõe sobre a organização do Sistema Único de Saúde no Município de São Paulo. Diário Oficial do Município 2004; 21 jul.

21. São Paulo. Lei no. 13.271. Dispõe sobre a descentralização das ações e serviços de saúde no Município de São Paulo, com a criação de entidades autárquicas hospitalares de regime especial. Diário Oficial do Município 2002; 5 jan.

22. São Paulo. Portaria n ${ }^{\circ}$. 11. Atribui responsabilidade pelo expediente das Coordenadorias de Saúde nas Subprefeituras satélite das regiões centro, leste, oeste e sul. Diário Oficial do Município 2005; 18 jan.

23. São Paulo. Decreto no. 46.209 de 15 de agosto. Dispõe sobre a transferência das Coordenadorias de Saúde das Subprefeituras que especifica para a Secretaria Municipal da Saúde. Diário Oficial do Município 2005; 16 ago.
24. São Paulo. Decreto nº 47.107. Dispõe sobre a integração das Coordenadorias Regionais de Saúde com a rede hospitalar municipal, para gestão da rede de serviços de saúde. Diário Oficial do Município 2006; 23 mar.

25. Departamento de Atenção Básica, Ministério da Saúde. Evolução do credenciamento e implantação da estratégia saúde da família. http://dtr2004. saude.gov.br/dab/localiza_cadastro.php (acessado em 28/Jul/2008).

26. São Paulo. Comunicado SMS no 04 . Diretrizes gerais para SMS - documento 2: implantação do Programa de Saúde da Família. Diário Oficial do Município 2001; 27 jun.

27. São Paulo. Portaria SMS no 3.822. Aprova o documento norteador à organização da atenção básica na cidade de São Paulo - Programa de Saúde da Família - PSF. Diário Oficial do Município 2002; 16 out.

28. Sousa MF. O PSF na cidade de São Paulo trabalhando em parceria: o compromisso possível. In: Sousa MF, Mendes A, organizadores. Tempos radicais da saúde em São Paulo: a construção do SUS na maior cidade brasileira. São Paulo: Editora Hucitec; 2003. p. 91-4.

29. Carapinheiro G. Saberes e poderes no hospital. 2 Ed. Porto: Afrontamento; 1993

30. Vieira-da-Silva LM, Hartz ZMA, Chaves SCL, Silva GAP, Paim JS. Análise da implantação da gestão descentralizada em saúde: estudo comparado de cinco casos na Bahia, Brasil. Cad Saúde Pública 2007; 23:355-70.

31. DiMaggio PJ, Powell WW. The iron cage revisited: institutional isomorphism and collective rationality in organizational fields. Am Sociol Rev 1983; 48:147-60.

32. Bousquat A, Cohn A, Elias PE. Implantação do Programa Saúde da Família e exclusão sócio-espacial no Município de São Paulo, Brasil. Cad Saúde Pública 2006; 22:1935-43.

33. Chalant JF. O gerencialismo e a ética do bem comum: a questão da motivação para o trabalho nos serviços públicos. In: VII Congreso Internacional del CLAD sobre la Reforma del Estado y de la Administración Pública. http://unpan1.un.org/ intradoc/groups/public/documents/CLAD/ clad0043316.pdf (acessado em 20/Jun/2008).

34. Di Pietro MSZ. Parcerias na administração pública. 2a Ed. São Paulo: Editora Atlas; 1997.

Recebido em 21/Ago/2008

Aprovado em 04/Nov/2008 